\title{
SABERES DOCENTES PARA O ENSINO DA ESCRITA: ESTUDO COMPARATIVO ENTRE ESTUDANTES DO CURSO DE PEDAGOGIA
}

\author{
TEACHER KNOWLEDGE TO THE TEACHING OF WRITING: COMPARATIVE STUDY BETWEEN \\ STUDENTS OF PEDAGOGY
}

\author{
Rejane Maria de Almeida Trisotto* \\ Universidade Federal do Rio de Janeiro - UFRJ, BR
}

\begin{abstract}
RESUMO: O presente artigo se inscreve no âmbito da pesquisa Saberes Docentes e Formação de professores para o Ensino da Escrita, do Laboratório de Estudos de Linguagem, Leitura, Escrita e Educação (LEDUC), da Faculdade de Educação da UFRJ, e é resultado de uma investigação em andamento que objetiva construir indicativos para sistematizar os saberes docentes necessários para o ensino da escrita entre estudantes dos cursos de Licenciatura em Pedagogia e Letras. Os estudos preliminares destacam duas categorias: saberes gerais, e saberes específicos para formação do pedagogo que é o primeiro a trabalhar com o ensino da escrita na escola.
\end{abstract}

PALAVRAS-CHAVE: saberes docentes; escrita; formação de professores.

ABSTRACT: This article falls within the scope of the research 'Teacher knowledge and teacher training for the teaching of writing', by the Laboratory of Language Studies (LEDUC) of the Department of Education of the Federal University of Rio de Janeiro (UFRJ). This study is a result of an ongoing investigation aiming to develop indicatives to systematize the teacher knowledge required to the teaching of writing to undergraduates of Pedagogy and Modern Languages courses. Considering the teacher as the subject that works first on the teaching of writing at schools, preliminary studies have highlighted two categories for teacher training: general knowledge and specific knowledge.

KEYWORDS: teacher knowledge; writing; teacher education.

\section{INTRODUÇÃO}

Para esta pesquisa concepções de Bakhtin são assumidas, considerando que para o autor o sentido da escrita se constitui não só pelos seus aspectos propriamente linguísticos, mas também, e principalmente, pela relação com o contexto extralinguístico, considerando a articulação que existe entre o texto e os fatores sociais, históricos, culturais e ideológicos de sua produção. Bakhtin (2002) afirma que nenhum discurso é individual, uma vez que se constrói por meio das relações entre seres sociais e todos os discursos sociais mantêm uma plena e permanente interação.

O uso da língua, para Bakhtin (2002), está intrinsecamente ligado às diversas esferas da atividade humana que determinam a produção de certos enunciados. Esses enunciados (escritos ou orais), "relativamente estáveis", estabelecidos pelas condições específicas e pelas finalidades de cada esfera, são chamados de gêneros do discurso. Os gêneros discursivos são histórica e socialmente construídos, visto que se relacionam diretamente às diferentes situações sociais que, por sua vez, os determinam com características temáticas, composicionais e estilísticas. É o que podemos observar a partir das seguintes considerações do autor:

O enunciado reflete as condições específicas e as finalidades de cada uma dessas esferas, não só por seu conteúdo (temático) e por seu estilo verbal, ou seja, pela seleção operada nos recursos da língua recursos lexicais, fraseológicos e gramaticais -, mas também, e sobretudo, por sua construção composicional. (BAKHTIN, 2002, p. 279).

A finalidade diz respeito especificamente ao sentido que tem para o escritor o seu texto, já o aspecto composicional refere-se à forma, ao gênero utilizado para comunicar o que se quer. É na junção desses dois aspectos que temos o texto. Pensar a escrita é olhar para sociedade, para as construções sociais que vão dando sentido às diversas formas de registros, além de olhar para a subjetividade de cada sujeito, da sua própria necessidade de expressão. 
Pesquisar os saberes docentes para o ensino da escrita nos faz refletir sobre que práticas de escrita são hoje priorizadas pela escola e quais práticas desejamos. Nesse sentido a teoria de Bakhtin (2002) ilumina tanto o caminho trilhado pela pesquisa, quanto as produções sobre Saberes Docentes.

Os estudos de Tardif (2002) e Gauthier (1998) orientam este trabalho e se apoiam em uma premissa de que existe uma base de saberes para o ensino. Esses autores pretendem destacar as seguintes bases: conceber o ensino como uma atividade profissional que se apoia num sólido repertório de conhecimentos; considerar os professores como práticos reflexivos; identificar na prática profissional o lugar de formação e de produção de saberes pelos práticos; instaurar normas de acesso à profissão; e estabelecer ligação entre as instituições universitárias de formação e as escolas da educação básica.

\section{q SABER, O QUE É?}

Gauthier (1998) definem o saber a partir de três concepções diferentes que se referem cada uma a um lugar particular: a subjetividade, o juízo e a argumentação. O 'saber' originário na subjetividade é todo tipo de certeza subjetiva produzida pelo pensamento racional, que se opõe à dúvida, ao erro e à imaginação, e se diferencia, igualmente, dos outros tipos de certeza, como a fé e as ideias preconcebidas. Portanto, saber é deter uma certeza subjetiva racional; é o fruto de um diálogo interior marcado pela razão.

O juízo mostra que o 'saber' é um juízo verdadeiro que não é fruto de uma intuição nem de uma representação subjetiva, mas a consequência de uma atividade intelectual, presente nos discursos que apresentam um juízo verdadeiro sobre um objeto, um fenômeno. O 'saber' se encontra unicamente nos juízos de fato. A argumentação também pode ser considerada como lugar do 'saber', definido como a atividade discursiva por meio da qual o sujeito tenta validar uma proposição ou uma ação, geralmente, por meio da lógica, da dialética ou da retórica. Por essa ótica, 'saber' alguma coisa não se reduz à simples atividade do juízo verdadeiro, mas, necessariamente, implica a capacidade de apresentar as razões dessa pretensa verdade do juízo. Segundo esse aspecto, o 'saber' se encontra também no discurso normativo, pois se pode argumentar sobre a sua validade.

Para Charlot (2005, p. 35) o que existe é uma relação com o saber, que o autor define do seguinte modo: "A relação com o saber é uma relação de sentido, portanto, de valor, entre um indivíduo (ou um grupo) e os processos ou produtos do saber". Nesse sentido, não pode haver um único saber, pois essa construção só é possível de ocorrer na troca entre sujeitos.

\subsection{Saberes docentes}

A pluridimensionalidade do 'saber profissional' dos professores é referendada por Gauthier (1998, p. 11), para quem "o saber docente é um saber composto de vários saberes oriundos de fontes diferentes e produzidos em contextos institucionais e profissionais variados".

Em suas atividades pedagógicas diárias, os professores planejam, executam o plano didático, escolhem as metodologias que julgam condizentes, elaboram as tarefas para os alunos, administram a sala de aula mantendo a ordem e a disciplina e constroem os instrumentos de avaliação. Em outras palavras, os professores tratam da gestão da matéria e da gestão da sala de aula e, por isso, necessitam utilizar diferentes 'saberes' necessários à consecução dos objetivos previamente definidos.

Partindo da afirmação de que o ensino é um ofício universal, portador de uma longa história e com origem que remonta à Grécia antiga, Gauthier (1998) sustentam que este ofício ainda mantém, em nossos dias, um papel fundamental para as sociedades humanas. Entretanto, apesar desta longevidade do ofício de ensinar, "mal conseguimos identificar os atos do professor que, na sala de aula, têm influência concreta sobre a aprendizagem dos alunos, e estamos apenas começando a compreender como se dá a interação entre educador e educandos" (GAUTHIER, 1998, p. 17). 
Gauthier (1998, p. 20) usa a sentença "conhece-te a ti mesmo", do oráculo de Delfos, para dizer que ainda se sabe muito pouco a respeito dos fenômenos que são inerentes ao ensino. Argumenta que ao "contrário de outros ofícios que desenvolveram um corpus de saberes, o ensino tarda a refletir sobre si mesmo". Segundo o autor, avançar na pesquisa de um repertório de conhecimentos sobre o ensino possibilita-nos enfrentar duas marcas que historicamente se interpuseram à pedagogia: de um ofício sem saberes e de saberes sem ofício.

O primeiro diz respeito à própria atividade docente que é exercida sem revelar os saberes que lhe são inerentes. Para Gauthier (1998, p. 20), "apesar do ensino ser uma atividade que se realiza desde a antiguidade, ainda se sabe muito pouco a seu respeito, e que convivemos com certas ideias preconcebidas que contribuem para o enorme erro de manter o ensino numa cegueira conceitual”. Existem formas restritas de conceber a atividade docente que consideram, por exemplo, que ensinar consiste apenas em transmitir conhecimentos, bastando, portanto, conhecer o conteúdo objeto de ensino, ou que é uma questão de talento, bom senso, intuição, ou, ainda, que demanda somente experiência e cultura.

Os saberes referentes ao conteúdo, à experiência e à cultura são essenciais no exercício da atividade docente, mas "tomá-los como exclusivos é mais uma vez contribuir para manter o ensino na ignorância" (GAUTHIER, 1998, p. 25) e reforçar a perpetuação de um ofício sem saberes.

O segundo obstáculo diz respeito aos saberes sem ofício, que têm sua origem nas Ciências da Educação, ou seja, são os conhecimentos produzidos nos centros acadêmicos. Muitos desses conhecimentos, segundo Gauthier (1998), foram produzidos sem levar em conta as condições concretas do exercício do magistério. Saberes que não se dirigiram ao professor real, cuja atuação se dá numa sala de aula concreta onde estão presentes muitas variáveis que interferem no processo de ensino-aprendizagem e exigem tomadas de decisão: "buscou-se formalizar o ensino reduzindo de tal modo a sua complexidade que ele não mais encontra correspondente na realidade" (GAUTHIER, 1998, p. 27). Para o autor, esse obstáculo contribuiu para a desprofissionalização da atividade docente ao reforçar para os professores a ideia de que a pesquisa universitária não lhes podia fornecer nada de realmente útil, e que, consequentemente, era muito mais pertinente que uns continuassem se apoiando na experiência pessoal, outros na intuição, outros no bom senso, etc.

Para o autor, reconhecer a existência de um repertório de conhecimentos reflete um olhar ressignificado para o professor, que passa a ser visto como um profissional autônomo que delibera, julga e toma decisões.

Do ponto de vista tipológico, Gauthier (1998) apresenta seis saberes docentes (Quadro 1 abaixo), que são demarcados dentro de uma prática pedagógica e se constituem de argumentos não verificados pelo método científico dentro de uma pluridimensionalidade relativa ao trabalho do professor.

Quadro 1 - Constituição dos Saberes, segundo Gauthier (1998)

\begin{tabular}{|l|l|}
\hline Saberes & Referência \\
\hline 1. Saberes disciplinares & A matéria \\
\hline 2. Saberes curriculares & O programa \\
\hline 3. Saberes das ciências da educação & Na formação ou em seu trabalho \\
\hline $\begin{array}{l}\text { 4. Saberes da tradição } \\
\text { pedagógica }\end{array}$ & O uso \\
\hline 5. Saberes experienciais & A jurisprudência particular \\
\hline $\begin{array}{l}\text { 6. Saberes da ação } \\
\text { pedagógica }\end{array}$ & $\begin{array}{l}\text { O repertório de conhecimentos do ensino ou } \\
\text { a jurisprudência pública validada }\end{array}$ \\
\hline
\end{tabular}
Fonte: GAUTHIER (1998, p. 28).

Para Gauthier, o saber disciplinar corresponde aos conteúdos científicos sobre os quais o professor compõe sua aula. Nessa instância o fato de o professor conhecer a matéria valida esse saber. 
O segundo listado é o saber curricular, que diz respeito à seleção e organização do programa que será desenvolvido na escola. Não basta conhecer a matéria, é necessário que o professor conheça como esses conhecimentos se transformam para virarem programa de ensino.

O saber das ciências da educação contribui para que o "professor compreenda muitas facetas de seu ofício e da educação de um modo geral” (1998, p. 31). Esses saberes se constituem durante a formação ou no trabalho profissional.

$\mathrm{O}$ saber da tradição pedagógica refere-se à maneira organizacional da escola, à forma ordenada como o professor se refere aos alunos no coletivo. Essa maneira de ser da escola já está aí há muitos séculos e, conforme argumenta o autor, ao invés de ser criticada e reformulada serve de molde para outros.

O saber experiencial está intimamente ligado ao hábito e aparece de uma forma muito particular e velada em salas de aula.

O saber da ação pedagógica difere do saber da experiência porque Gauthier (1998) ressalta que ocorre nesse ponto o momento em que o que é feito em sala de aula se torna público e é validado através de pesquisas. O autor destaca que esse saber ainda permanece fechado nas salas de aula, ou que, embora haja investimentos em pesquisas e enormes produções sobre a prática pedagógica, nota-se pouco efeito no trabalho docente, porque cada professor permanece sozinho em seu ofício. Para Gauthier (1998, p. 34), "Não poderá haver profissionalização do ensino enquanto esse tipo de saber não for mais explicitado, visto que os saberes da ação pedagógica constituem um dos fundamentos da identidade profissional do professor.”.

Tardif (2002) apresenta cinco saberes docentes que são resultantes de uma gama bastante diversa de fontes. $\mathrm{O}$ autor enfatiza a forma com que esses saberes vão sendo integrados na vida profissional do professor e se alterando também a partir de suas muitas ressignificações. O Quadro 2 expõe a tipologia indicada pelo autor destacando as fontes sociais de aquisição e modos de integração no trabalho docente.

Quadro 2 - Constituição dos Saberes, segundo Tardif (2002)

\begin{tabular}{|l|l|l|}
\hline Saberes dos Professores & Fontes sociais de aquisição & $\begin{array}{l}\text { Modos de integração no } \\
\text { trabalho docente }\end{array}$ \\
\hline Saberes pessoais dos professores & $\begin{array}{l}\text { A família, o ambiente de vida, a } \\
\text { educação no sentido lato, etc. }\end{array}$ & $\begin{array}{l}\text { Pela história de vida e pela } \\
\text { socialização. }\end{array}$ \\
\hline $\begin{array}{l}\text { Saberes provenientes da } \\
\text { formação escolar anterior }\end{array}$ & $\begin{array}{l}\text { A escola primária e secundária, } \\
\text { os estudos de pós-secundário não } \\
\text { especializados, etc. }\end{array}$ & $\begin{array}{l}\text { Pela formação e pela socialização } \\
\text { pré-profissionais. }\end{array}$ \\
\hline $\begin{array}{l}\text { Saberes provenientes da } \\
\text { formação profissional para o } \\
\text { magistério }\end{array}$ & $\begin{array}{l}\text { Os estabelecimentos de formação } \\
\text { de professores, os estágios, os } \\
\text { cursos de reciclagem, etc. }\end{array}$ & $\begin{array}{l}\text { Pela formação e pela socialização } \\
\text { profissionais nas instituições de } \\
\text { formação de professores. }\end{array}$ \\
\hline $\begin{array}{l}\text { Saberes provenientes dos } \\
\text { programas e livros didáticos } \\
\text { usados no trabalho }\end{array}$ & $\begin{array}{l}\text { A utilização das “ferramentas" } \\
\text { dos professores: programas, } \\
\text { livros didáticos, cadernos de } \\
\text { exercícios, fichas, etc. }\end{array}$ & $\begin{array}{l}\text { Pela utilização das "ferramentas" } \\
\text { de trabalho, na sua adaptação às } \\
\text { tarefas. }\end{array}$ \\
\hline $\begin{array}{l}\text { Saberes provenientes de sua } \\
\text { própria experiência na profissão, } \\
\text { na sala de aula e na escola. }\end{array}$ & $\begin{array}{l}\text { A prática do ofício na escola, na } \\
\text { sala de aula, a experiência dos } \\
\text { pares, etc. }\end{array}$ & $\begin{array}{l}\text { Pala prática do trabalho e pela } \\
\text { socialização profissional. }\end{array}$ \\
\hline
\end{tabular}

Fonte: Tardif (2002, p. 63).

Considerando que esses saberes são provenientes de diferentes fontes e que os professores estabelecem diferentes relações com eles, tipologicamente Tardif (2002) os classifica em: saberes da formação profissional (das ciências da educação e da ideologia pedagógica), compreendidos como o conjunto de saberes transmitidos pelas instituições de formação de professores; saberes disciplinares, correspondentes aos diversos campos do conhecimento sob a forma de disciplina - são saberes sociais definidos e selecionados pela 
instituição universitária e incorporados na prática docente; saberes curriculares, que correspondem aos discursos, objetivos, conteúdos e métodos a partir dos quais a instituição escolar categoriza e apresenta os saberes sociais por ela definidos e selecionados como modelos da cultura erudita e de formação para a cultura erudita; e, por fim, saberes experienciais, que são aqueles saberes que brotam da experiência e são por ela validados, incorporando experiência individual e coletiva sob a forma de habitus e de habilidades, de saber-fazer e de saber-ser.

Enquanto para Gauthier (1998) os saberes da experiência são feitos de pressupostos e de argumentos não verificados por meio de método científico, para Tardif (2002) esses saberes formam um conjunto de representações a partir dos quais os professores orientam sua profissão.

\subsection{Saberes docentes para o Ensino da Escrita}

A partir de respostas dadas em instrumento de pesquisa aplicado em maio de 2011, a 75 alunos dos três primeiros períodos iniciais e 20 alunos do penúltimo período do Curso de Pedagogia da UFRJ, matriculados nos três turnos em que o curso é oferecido pela instituição (matutino, vespertino e noturno), foi possível elaborar algumas aproximações do que se espera de um professor que ensine escrita na escola na percepção desses estudantes. Optou-se por aplicar o mesmo instrumento no grupo de formandos para compreender se a formação que tiveram até o momento conseguiu ampliar a percepção sobre o ensino da escrita durante o curso.

Para esta análise vamos nos deter na última questão do questionário, cujo enunciado foi:

10. Enumere três qualidades profissionais que você julga necessárias para que o professor de escrita realize um bom trabalho.

As repostas foram previamente separadas em grupos de saberes: o primeiro incorpora elementos mais fluidos e de ordem mais geral; e o segundo reúne importantes saberes específicos para a formação do pedagogo, que é o primeiro a trabalhar com o ensino da escrita na escola.

\subsubsection{Primeira categoria: saberes gerais do professor}

Essa categoria incorpora elementos dos saberes apresentados pelos autores Tardif, Lessard e Lahaye (1991) e Gauthier (1998). Os alunos indicaram uma gama muito grande de adjetivos que correspondem a importantes fatores que, independentemente da área de atuação do docente, contribuem para uma prática pedagógica de qualidade. Percebemos que a atividade docente, por conter inúmeras tarefas, acaba dificultando a escolha de situações específicas para a escrita entre alunos que acabam de ingressar em um curso de Pedagogia e que ainda não receberam as bases das disciplinas de Alfabetização e Letramento, Didática da Língua Portuguesa e Prática de Ensino das Séries Iniciais do Ensino Fundamental. Por outro lado, o grupo de 20 alunos formandos já tiveram essas importantes discussões e inclusive realizaram seus estágios. Essas disciplinas de ordem prática e teórica contribuíram para que pudessem analisar o ensino com diferentes contornos.

Tardif (2002, p. 36) define o saber docente "como um saber plural, formado pelo amálgama, mais ou menos coerente, de saberes oriundos da formação profissional e de saberes disciplinares, curriculares e experienciais". Nessa perspectiva, os saberes profissionais dos professores são temporais, plurais e heterogêneos, personalizados e situados, e carregam as marcas do ser humano. 
Listamos as ocorrências distribuídas em tabelas ${ }^{1}$, salientando que todas as características constantes nas tabelas 1 e 2 estão sendo consideradas, neste estudo, como saberes gerais para o ensino e não estão atreladas especificamente ao ensino da escrita.

Tabela 1 - Ocorrências de saberes gerais entre os 75 alunos dos três primeiros períodos

\begin{tabular}{|c|c|c|}
\hline Saberes Docentes & Ocorrências & Percentual \\
\hline Criatividade & 14 & $18,6 \%$ \\
\hline Boa didática & 10 & $13,3 \%$ \\
\hline Paciência & 7 & $9,3 \%$ \\
\hline Ética & 6 & $8 \%$ \\
\hline Conhecimento geral & 6 & $8 \%$ \\
\hline Dinamismo & 6 & $8 \%$ \\
\hline Dedicado & 4 & $5,3 \%$ \\
\hline Clareza & 3 & $4 \%$ \\
\hline Comprometimento & 3 & $4 \%$ \\
\hline Atenção/atencioso & 3 & $4 \%$ \\
\hline Competente & 3 & $4 \%$ \\
\hline Ser crítico & 2 & $2,6 \%$ \\
\hline Determinação & 2 & $2,6 \%$ \\
\hline Gostar do que faz & 2 & $2,6 \%$ \\
\hline Responsável & 2 & $2,6 \%$ \\
\hline Autoconhecimento & 2 & $2,6 \%$ \\
\hline Valor cultural & 2 & $2,6 \%$ \\
\hline Informação & 2 & $2,6 \%$ \\
\hline Sensibilidade para perceber dificuldades dos alunos & 1 & $1,3 \%$ \\
\hline Autonomia & 1 & $1,3 \%$ \\
\hline Inteligente & 1 & $1,3 \%$ \\
\hline Dialogar & 1 & $1,3 \%$ \\
\hline Prática & 1 & $1,3 \%$ \\
\hline Procurar temas diversos & 1 & $1,3 \%$ \\
\hline Trabalhar em equipe & 1 & $1,3 \%$ \\
\hline Aprender & 1 & $1,3 \%$ \\
\hline Atualizado & 1 & $1,3 \%$ \\
\hline Ter motivação & 1 & $1,3 \%$ \\
\hline Observador & 1 & $1,3 \%$ \\
\hline Pesquisador & 1 & $1,3 \%$ \\
\hline Inovador & 1 & $1,3 \%$ \\
\hline Boa relação com alunos & 1 & $1,3 \%$ \\
\hline Transmitir credibilidade no que está ensinando & 1 & $1,3 \%$ \\
\hline Visão de avaliação diferente do método tradicional & 1 & $1,3 \%$ \\
\hline Construtivista & 1 & $1,3 \%$ \\
\hline Abertura a mudanças & 1 & $1,3 \%$ \\
\hline Ter certeza de sua escolha & 1 & $1,3 \%$ \\
\hline Emoção & 1 & $1,3 \%$ \\
\hline
\end{tabular}

\footnotetext{
$1 \mathrm{O}$ percentual nas tabelas apresentadas corresponde à proporção de alunos que indicaram a característica correspondente nas respostas, e não ao número de ocorrências.
} 


\begin{tabular}{l|c|c}
\hline Amor ao ensinar & 1 & $1,3 \%$ \\
\hline Conhecimento sobre técnica e prática & 1 & $1,3 \%$ \\
\hline Sinceridade & 1 & $1,3 \%$ \\
\hline Compreensão & 1 & $1,3 \%$ \\
\hline
\end{tabular}

Tabela 2 - Ocorrências de saberes gerais entre os 20 alunos do penúltimo período

\begin{tabular}{l|l|c}
\hline Saberes Docentes & Ocorrências & Percentual* \\
\hline Comprometimento & 5 & $25 \%$ \\
\hline Capacitação & 4 & $20 \%$ \\
\hline Conhecimento geral & 3 & $15 \%$ \\
\hline Paciência & 3 & $15 \%$ \\
\hline Criatividade & 2 & $10 \%$ \\
\hline Pró ativo & 2 & $10 \%$ \\
\hline Valorize aprendizagem & 1 & $5 \%$ \\
\hline Ser reflexivo & 1 & $5 \%$ \\
\hline Respeito & 1 & $5 \%$ \\
\hline Objetividade & 1 & $5 \%$ \\
\hline Dinamismo & 1 & $5 \%$ \\
\hline Humildade & 1 & $5 \%$ \\
\hline Força de vontade & 1 & $5 \%$ \\
\hline Gostar de ensinar & 1 & $5 \%$ \\
\hline Organizado & 1 & $5 \%$ \\
\hline Saber se expressar & 1 & $5 \%$ \\
\hline
\end{tabular}

Essas características são descritas pelos estudantes com palavras que indicam elementos contidos nos 'saberes pessoais dos professores', como é o caso de ética, dinamismo, comprometimento, paciência dentre outros. São traços pessoais que muito contribuem para que a prática educacional de modo geral seja fortalecida.

Os 'saberes provenientes da formação escolar anterior' do professor aparecem nesse grupo com a indicação de conhecimento geral e atualizado. Os 'saberes provenientes da formação profissional para o magistério' estão descritos com expressões como boa didática, visão de avaliação diferente de métodos tradicionais, pesquisador, dentre outras.

Tardif (2002) valoriza a pluralidade e a heterogeneidade do saber docente, destacando a importância dos saberes da experiência. Essa questão também revelou algumas características dos saberes profissionais segundo a definição de "epistemologia da prática profissional dos professores", compreendida como o estudo do conjunto dos saberes utilizados realmente pelos profissionais em seu espaço de trabalho cotidiano para desempenhar todas as suas tarefas. Nesse caso destacamos visão de avaliação diferente do método tradicional, trabalhar em equipe e boa relação com alunos.

Identificamos entre os dois grupos de alunos a recorrência de alguns termos, como paciência, dinamismo, comprometimento, dentre outros.

\subsubsection{Segunda categoria: saberes específicos para o ensino da escrita}

Aqui reunimos as indicações dos alunos que constituem um grupo de saberes que se relacionam ao trabalho com a escrita na escola. Ressaltamos que muitas características elencadas são também importantes para desenvolver um bom trabalho em todas as áreas da educação, porém, é na hora de ensinar a escrita que se destacam. 
Tabela 3 - Ocorrências de saberes específicos entre os 75 alunos dos três primeiros períodos

\begin{tabular}{|c|c|c|c|}
\hline & Saberes Docentes & Ocorrências & Percentual* \\
\hline 1 & Ser bom leitor & 23 & $30,6 \%$ \\
\hline 2 & Qualidade na sua própria escrita & 15 & $20 \%$ \\
\hline 3 & Domínio do assunto (regras, literatura) & 14 & $18,6 \%$ \\
\hline 4 & Incentivar a leitura & 6 & $8 \%$ \\
\hline 5 & Manter-se informado com as regras ortográficas & 5 & $6,6 \%$ \\
\hline 6 & Conhecer e valorizar a realidade do aluno, vocabulário & 4 & $5 \%$ \\
\hline 7 & Valorizar a escrita & 1 & $1,3 \%$ \\
\hline 8 & Trabalhar em sala de aula com temas de interesse dos alunos & 1 & $1,3 \%$ \\
\hline
\end{tabular}

Tabela 4 - Ocorrências de saberes específicos entre os 20 alunos do penúltimo período Saberes Docentes

\begin{tabular}{|c|c|c|c|}
\hline 1 & Saber escrever, ser escritor & 4 & $20 \%$ \\
\hline 2 & Conhecimento específico & 3 & $15 \%$ \\
\hline 3 & ncentivar escrita da opinião dos alunos & 3 & $15 \%$ \\
\hline 4 & Saber norma culta & 3 & $15 \%$ \\
\hline 5 & Puvir opinião dos alunos & 2 & $10 \%$ \\
\hline 6 & Pomínio do conteúdo & 2 & $10 \%$ \\
\hline 7 & Ser leitor & 1 & $5 \%$ \\
\hline 8 & nteresse em leitura & 1 & $5 \%$ \\
\hline 9 & Fonceber linguagem como interação & 1 & $5 \%$ \\
\hline & Fonhecer técnica de ensino da escrita & 1 & $5 \%$ \\
\hline
\end{tabular}

A grande maioria dos estudantes pesquisados indicou saberes de ordem geral (cf. tabelas 1 e 2), ficando os saberes específicos reduzidos, conforme se observa nas tabelas 3 e 4. Importantes reflexões, contudo, já são possíveis para o início de nossa pesquisa, que também acompanha a evolução e complexidade da reflexão desses alunos ao longo de sua formação.

Para facilitar nossa análise esse tópico foi subdividido em cinco categorias, para que possamos traçar uma tipologia dos saberes específicos para o ensino da escrita. Na análise e na tabela 5 daremos destaque a algumas diferenças e aproximações entre as respostas dadas por alunos que iniciam o curso (dos três primeiros períodos) e ainda não tiveram disciplinas específicas que refletem sobre o papel da escrita, e alunos do penúltimo período, que inclusive já realizaram seus estágios nos Anos Iniciais do Ensino Fundamental e da Educação Infantil.

Cada categoria é composta da junção de itens indicados nas tabelas 3 e 4 que se referiam ao mesmo conjunto de saberes indicados pelos alunos.

Tabela 5 - Síntese do percentual de ocorrências de saberes específicos entre os dois grupos de alunos (iniciantes e formandos)

\begin{tabular}{l|c|c}
\hline \multicolumn{1}{c|}{ Saberes Específicos para o Ensino da Escrita } & $\begin{array}{c}\text { Percentual de alunos } \\
\text { iniciantes }\end{array}$ & $\begin{array}{c}\text { Percentual de alunos } \\
\text { formandos }\end{array}$ \\
\hline a) Valorizar a leitura do docente e do aluno & $\begin{array}{c}\mathbf{3 8 , 6 \%} \\
\text { (cf. Tabela 3, itens 1 e 4) }\end{array}$ & $\begin{array}{c}\mathbf{1 0 \%} \\
\text { (cf. Tabela 4, itens 7 e 8) }\end{array}$ \\
\hline $\begin{array}{c}\mathbf{4 0} \% \\
\mathbf{2 5 , 3 \%} \\
\text { b) Domínio de regras ortográficas e norma culta (conteúdo) }\end{array}$ \\
\hline c) Valorizar a escrita do docente e do aluno & $\begin{array}{c}\mathbf{2 2 , 6 \%} \\
\text { (cf. Tabela 4, itens 2, 4 e 6) }\end{array}$ \\
\hline d) Conhecer e valorizar a realidade do aluno e seu vocabulário & $\begin{array}{c}\mathbf{5 , 3 \%} \\
\text { (cf. Tabela 4, itens 1, 3 e 10) }\end{array}$ \\
\hline e) Trabalhar com temas do interesse do aluno & $\begin{array}{c}\mathbf{3 0 \%} \\
\text { (cf. Tabela 3, item 8) }\end{array}$ & (cf. Tabela 4, item 5, 3 e 9) \\
\hline
\end{tabular}




\section{a) Valorização da leitura do docente e do aluno}

Esse tópico está em primeiro lugar nas ocorrências dos alunos ingressantes, somando 38,6\% entre os itens Ser bom leitor e Incentivar a leitura (cf. Tabela 3). Esse posicionamento indica uma situação já discutida na bibliografia ${ }^{2}$, que revela o quanto ainda se pensa que a escrita é consequência da leitura. Concordamos que o contato com uma diversidade de textos proporciona uma intimidade com a utilização que se faz da escrita em diferentes circunstâncias e o reconhecimento de diferentes gêneros textuais. No entanto, a visão naturalizante de que quem lê, escreve, ainda é muito comum na escolarização, deixando a escrita em segundo lugar.

A esse respeito os PCN de Língua Portuguesa fazem o seguinte comentário:

A relação que se estabelece entre leitura e escrita, entre o papel de leitor e de escritor, no entanto, não é mecânica: alguém que lê muito não é, automaticamente, alguém que escreve bem. Pode-se dizer que existe uma grande possibilidade de que assim seja. É nesse contexto - considerando que o ensino deve ter como meta formar leitores que sejam também capazes de produzir textos coerentes, coesos, adequados e ortograficamente escritos - que a relação entre essas duas atividades deve ser compreendida. (BRASIL, 1996, p. 52-53).

Apesar do texto dos PCN de Língua Portuguesa afirmar que quem lê muito não necessariamente escreve bem, acaba por restringir a escrita ao domínio de um código ao referir-se a textos coerentes, coesos e adequados ortograficamente. Essa questão necessita ser desmistificada pela escola, as crianças desde cedo devem ser convidadas a fazer registros variados e cada vez mais fortalecer a intimidade com a escrita significativa e contextualizada.

Fica evidente, na tabela 5, o quanto os alunos que estão concluindo o curso já mudaram essa percepção, de que a leitura é um domínio que resulta em boa escrita; para esses encontramos um percentual de 10\% somando os itens Ser leitor e Interesse na leitura (cf. Tabela 4). Para Masello Leta (2005), leitura e escrita pressupõem habilidades diferentes; a autora enfatiza:

Há pessoas que podem ser capazes de ler, mas não serem capazes de escrever; ou outras que podem ler fluentemente, e não escrever bem. Portanto, há diferenças fundamentais entre as habilidades e conhecimentos empregados na leitura e aqueles empregados na escrita. (2005, p. 71).

\section{b) Domínio de regras ortográficas e norma culta (conteúdo)}

Unindo os itens elencados pelos estudantes ingressantes, Domínio de assunto e regras e Manter-se informado com regras ortográficas e norma culta (cf. Tabela 3), e pelos formandos Saber norma culta, Conhecimento Específico e Domínio do conteúdo (cf. Tabela 4), registramos o percentual de 25,3\% entre os primeiros e 40\% entre os últimos. Embora seja imprescindível conhecer a estrutura da língua para ter uma boa escrita, essa compreensão de que a norma culta, a ortografia e as regras compõem o maior objetivo para a escrita está de acordo com o que a escola vem praticando há muito tempo ao treinar alunos para dominar certos instrumentos de linguagem.

Para Castro (2008, p. 152), "a vida vai exigir que se aprenda a viver com o princípio da realidade, isto, porém, também não é motivo para decretar, logo na infância, a interdição do princípio do prazer.” O autor salienta que a preocupação exagerada da escola com a regra acaba por formar alunos que "passam o resto de suas vidas sob os efeitos dos textos que não puderam ser escritos".

Podemos inferir que esse resultado expresso pelos alunos formandos está ligado a concepções de escrita que são partilhadas em sua formação ao longo do curso, dinâmicas reforçadoras de um ensino que busca corrigir e padronizar.

\footnotetext{
${ }^{2}$ Ver: TRISOTTO (2010).
} 


\section{c) Valorização da escrita do docente e do aluno}

Um professor que escreve e valoriza a escrita em sala de aula pode mais facilmente instigar seus alunos para o registro em diferentes contextos de sua vida. Consideramos um ponto muito importante o professor não só escrever para si, mas também escrever com e para seus alunos.

Parece-nos que a questão de conduzir a escrita estabelecendo limites para o aluno eliminar dificuldades não tem sido um bom caminho, já que a escola tem se utilizado por muitos anos dessa metodologia em livros didáticos. Conforme Bakhtin (2002), o conteúdo da consciência individual é formado nas contínuas e progressivas interações de que o indivíduo participa:

A consciência adquire forma e existência nos signos criados por um grupo organizado no curso de suas relações sociais. Os signos são o alimento da consciência individual, a matéria de seu desenvolvimento, e ela reflete sua lógica e suas leis. [...] Os indivíduos não recebem a língua pronta para ser usada; eles penetram na corrente da comunicação verbal; ou melhor, somente quando mergulham nessa corrente é que sua consciência desperta e começa a operar. (BAKHTIN, 2002, p. 35-36, 108).

Considerando o que nos aponta o autor, limitar o aluno e demarcar espaços de escrita não proporciona o mergulho apropriado para que a consciência do que deve ser lapidado seja revista. É pela escrita livre e significada que é possível construir uma autoria e ir aos poucos melhorando todos os importantes aspectos da escrita. Um professor que valoriza a escrita em sua vivência, divide esse gosto com seus alunos e, da mesma forma, incentiva a escrita em suas aulas, estará atento para criatividade, expressão de sentimentos e autoria da produção que propõe aos educandos durante o desenvolvimento de seu trabalho.

Entre os alunos iniciantes do curso o percentual foi de 22,6\% entre os itens Qualidade na sua própria escrita e Valorizar a escrita (cf. Tabela 3). Cremos que o índice sensivelmente maior com percentual de 40\% somando os itens Saber escrever, ser escritor; Incentivar escrita da opinião dos alunos e Conhecer técnica de ensino da escrita (cf. Tabela 4) para este tópico entre os alunos formandos é revelador de sua formação, que em disciplinas como Alfabetização e Letramento, Didática do Ensino de Língua Portuguesa e Prática de Ensino dos Anos Iniciais são colocados em contato com bibliografias e discussões que corroboram com a tese de que precisamos estar atentos à produção do aluno e trabalhar de forma prospectiva, valorizando sua autoria e protagonismo durante esse processo.

\section{d) Conhecimento e valorização da realidade do aluno e seu vocabulário}

Essa importante característica apareceu com um percentual de 5,3\% (cf. Tabela 3) entre os ingressantes do curso no item Conhecer e valorizar a realidade do aluno, vocabulário; e nas respostas dadas pelos alunos formandos foi denominada como Conceber linguagem como interação, Ouvir opinião dos alunos e Incentivar escrita da opinião dos alunos (cf. Tabela 4), aparecendo com um percentual de $30 \%$. Um professor que conhece e valoriza a realidade do seu aluno e seu vocabulário poderá ter uma intervenção mais positiva quando propuser escritas alinhadas ao interesse e cultura de que participam. Para Castro (2008, p. 135),

\footnotetext{
$\mathrm{O}$ ato de escrever tem múltiplos significados, tanto para quem escreve quanto para quem lê o escrito. Ao eleger sentidos aparentemente mais práticos, subestimando ou mesmo proibindo aqueles que parecem menos úteis - como o sentido catártico ou confessional -, em nome de aprendermos "o que interessa", criamos uma lacuna de sentido que invade toda a produção dos sujeitos. Cada texto objetivo produzido a duras penas por nossos alunos carrega a sombra de algo que precisava ser escrito e não foi.
}

Valorizar o aspecto de autoria da escrita do aluno é dar um passo importante para romper com a prática de uma escrita instrumental na direção de uma escrita com significados. É justamente a preocupação elevada com a norma que por vezes limita a criação, juntamente com as propostas de escrita descontextualizadas da vida do aluno.

A escrita na escola ainda é um instrumento ideológico usado para excluir e demonstrar que a escrita correta é a que a escola usa e não a de que se valem diversos grupos sociais na sua comunicação. "Escreve-se nos alunos - crianças, jovens e adultos - o traço da obediência e da conformação, a necessidade de evitar os 
riscos, os riscos do papel e os riscos de se aventurar pelas trilhas do desconhecido" (KRAMER, 2000, p. 111).

Notamos que o índice de apontamento dessa característica entre estudantes formandos foi mais elevado que entre os alunos ingressantes e isso sugere que os diálogos travados durante sua formação, seja com professores e/ou com textos diversos, refletiram positivamente para que essa característica fosse reconhecida como um importante saber para o ensino da escrita.

\section{e) Trabalho com temas do interesse do aluno}

Embora esse item tenha aparecido em apenas um questionário do grupo dos alunos ingressantes no curso de Pedagogia (cf. Tabela 3), optamos por mantê-lo nessa tentativa de mapear a tipologia de saberes docentes para o ensino da escrita por o considerarmos fundamental.

O universo escolar feito de livros, cadernos, quadro e muitas horas de escrita e leitura nem sempre se utiliza de temas que realmente estejam de acordo com o interesse do aluno. A escrita com sentido, livre de moldes e limitações impostas pelo medo de errar, corrobora o que Benjamin (1987) afirma:

As opiniões para o aparelho gigante da vida social são o que é o óleo para as máquinas; ninguém se posta diante de uma turbina e a irriga com óleo de máquina. Borrifa-se um pouco em rebites e juntas ocultos, que é preciso conhecer. (1987, p. 11).

A enxurrada de atividades que objetivam melhorar a ortografia dos alunos não atinge o que pretende porque está relacionada ao que Benjamin descreve como "irrigar". A forma sutil e subjetiva de construir a escrita na escola acontece quando o professor conhece o texto de seu aluno, se interessa sobretudo pela expressão e criatividade do texto. O "borrifar" está ligado a uma atividade que pode ocorrer em vários momentos ao longo da prática docente, mas que não massacra, está oculta porque justamente não deseja ser o centro do processo da escrita.

A partir da análise dentro da teoria de Bakhtin podemos afirmar que na escola temos muito mais de monologismo do que de polifonia. Uma escola monológica é aquela em que um único sentido sobressai, impedindo os demais de virem à tona. Esse tipo de trabalho com a linguagem exclui a dimensão criadora; a língua passa a servir, numa análise mais ampla, até mesmo como um instrumento de reprodução do sistema. Já na polifonia,

Não existe nem a primeira nem a última palavra, e não existem fronteiras para um contexto dialógico. [...] Em qualquer momento do diálogo existem as massas enormes e ilimitadas de sentidos esquecidos que serão recordados e reviverão em um contexto e num aspecto novo. (BAKHTIN, 1985, p. 54).

A polifonia, para Bakhtin, é um jogo dramático de vozes que somado cria um diálogo entre diversos contextos num caráter bem diferente do parafrasear que a escola utiliza e da escrita sem significado. Sem a possibilidade da polifonia se anula o diálogo e a reconstrução possível de sentidos e se limita a escrita a mero trabalho técnico e de reprodução.

Essa primeira análise revela o quanto o papel da escola contribuiu para que os estudantes de Pedagogia iniciantes reproduzissem, de alguma forma, ideias difundidas em práticas instrumentais de escrita nas quais foram formados; bem como o importante papel da formação durante o curso que pode ressignificar algumas concepções - eis o grande desafio dos formadores.

\section{CONSIDERAÇÕES FINAIS}

Gauthier (1998), ao defender para a docência a perspectiva de um "Ofício feito de saberes", implementa esforços para a constituição de uma Teoria Geral da Pedagogia. Amparados nessa perspectiva e com foco em nosso viés de pesquisa, que é a escrita, notamos que é indispensável que o processo de formação do pedagogo congregue elementos que possam lhe dar suporte para trabalhar com a escrita na escola. Ao 
pesquisar os saberes do ensino da escrita, chegamos ao mesmo ponto de Gauthier (1998), crendo que seja imprescindível encaminhar uma pesquisa que lance bases para que esse ofício ganhe a sua especificidade.

É nessa perspectiva que Gauthier (1998, p. 256) defende a ideia de uma "epistemologia da prática” com a finalidade de revelar os saberes docentes, "compreender como são integrados concretamente nas tarefas dos profissionais e como estes os incorporam, produzem, utilizam, aplicam e transformam em função dos limites e dos recursos inerentes às suas atividades de trabalho".

Os estudos sobre a escrita na escola e a tentativa de romper com uma prática que busque apenas o domínio da técnica do aluno - a fim de instaurar uma prática de escrita humanizada que possa convergir para uma descoberta de quem o aluno é, que seja um momento de comunicar desejos, sentimentos e percepções -, necessitam de um profissional também preparado para fazer isso acontecer. Estudar os saberes docentes para o ensino da escrita contribui para essa profissionalização e para legitimar práticas docentes que nos apontam esses caminhos.

Percebemos que, embora haja um esforço para mudança de paradigmas de trabalho com a escrita, ainda se sobrepõe a valorização da Língua Portuguesa que fortalece a paráfrase, a reprodução e o domínio de habilidades para trabalhar com o código escrito, tão comum em livros didáticos escolares. O processo de autoria, de uma escrita que fortaleça o conhecimento de si mesmo e dos outros precisa ser perseguido na prática docente para que os alunos possam escrever sobre o que lhes interessa, sobre suas experiências e assim o espaço para escrita verdadeiramente seja garantido pela escola.

Para Kramer (2000, p. 116), "a escrita traz a possibilidade de pensar o que se fez e viveu, ampliando o raio de ação e reflexão". Ainda segundo a autora, o grande problema do afastamento do ensino da escrita em relação ao mundo real do aluno, aos seus sentimentos, a sua autoria de um texto, não se trata apenas de não desenvolver o gosto pela escrita, mas é mais grave que isso: "o problema é que isso pode ser um sintoma do nosso processo de desumanização". (2000, p. 116).

A prática da escrita nos cursos de formação merece reflexões mais profundas que este artigo não foi capaz de abarcar. No entanto, a análise das respostas dadas por estudantes do Curso de Pedagogia da UFRJ matriculados nos três primeiros períodos e alunos formandos deixa uma importante sinalização sobre as concepções de escrita com que os professores que irão ensinar escrita iniciam sua formação e depois como essas noções se alteram. Se queremos uma educação que promova a democracia e a formação de sujeitos críticos que sejam capazes de usar a escrita como forma de expressão, precisamos repensar a formação de quem irá fazer esse trabalho na escola, o professor.

\section{REFERÊNCIAS}

BRASIL. Ministério da Educação e do Desporto. Secretaria de Educação Fundamental. Parâmetros Curriculares Nacionais - Língua Portuguesa ensino fundamental. Brasília: MEC/SEF-1996. 3 v.

BAKHTIN, M. Marxismo e filosofia da linguagem. 9. ed. São Paulo: Hucitec; Annablume, 2002. Estética da criação verbal. 3. ed. São Paulo: Martins Fontes, 1985.

BENJAMIN, W. Obras Escolhidas I - rua de mão única. São Paulo: Brasiliense, 1987.

CASTRO, M. M. Por que escrever? Uma discussão sobre o ensino da produção textual. 2. ed. Rio de Janeiro: [s.n.], 2008.

CHARLOT, B. Relação com o saber, formação dos professores e globalização: questões para a educação hoje. Porto Alegre: Artes Médicas, 2005.

GAUTHIER, C. Por uma Teoria da Pedagogia: pesquisas contemporâneas sobre o saber docente. Ijuí: Unijuí, 1998. 
KRAMER, S. Escrita, experiência e formação - múltiplas possibilidades de criação de escrita. In: ENCONTRO NACIONAL DE DIDÁTICA E PRÁTICA DE ENSINO (ENDIPE) - Linguagens, espaços e tempos no ensinar e aprender. Anais... Rio de Janeiro: DP\&A, 2000. p. 105-121.

MASELLO LETA, M. Relação dos professores com o ensino da escrita: um estudo em duas escolas do Rio de Janeiro. Rio de Janeiro: H. P. Comunicações Associados, 2005.

TARDIF, M.; LESSARD, C.; LAHAYE, L. Esboço de uma problemática do saber docente. Teoria छ Educação, v. 1, n. 4, p. 215-253, 1991.

TARDIF, M. Saberes docentes e formação profissional. 2. ed. Petrópolis: Vozes, 2002.

TRISOTTO, R. M. A. Escrita e formação: o que escrevem os professores sobre a prática de ensinar a escrever? In: SEMANA DA EDUCAÇÃO, 15.: Memórias, Pesquisas e Práticas Pedagógicas: 60 anos da EDU-UERJ. Anais... Rio de Janeiro, 2010. Rio de Janeiro: UERJ, 2010. v.1, p. 65-75.

Recebido em 29/o8/2011. Aprovado em 20/12/2011. 